Acta Crystallographica Section B

Structural

Science

ISSN 0108-7681

\section{Richard M. Ibberson, ${ }^{a *}$ \\ Mark T. F. Telling ${ }^{\mathrm{a}}$ and Simon Parsons $^{\mathrm{b}}$}

aISIS Facility, CCLRC - Rutherford Appleton Laboratory, Chilton, Didcot, Oxfordshire OX11 OQX, England, and ${ }^{\mathbf{b}}$ School of Chemistry, The University of Edinburgh, King's Buildings, West Mains Road, Edinburgh EH9 3JJ, Scotland

Correspondence e-mail: r.m.ibberson@rl.ac.uk

\title{
Structure determination and phase transition behaviour of dimethyl sulfate
}

The crystal structures of phase I and phase II of dimethyl sulfate, $\left(\mathrm{CH}_{3} \mathrm{O}\right)_{2} \mathrm{SO}_{2}$, have been determined using complementary high-resolution neutron powder and single-crystal $\mathrm{X}$-ray diffraction techniques. Below its melting point of $241 \mathrm{~K}$ dimethyl sulfate crystallizes in an orthorhombic structure (I) in the space group $F d d 2$. On cooling below $\sim 175 \mathrm{~K}$ the crystal transforms to a monoclinic structure (II) in the space group $I 2 / a$. The molecule is located on a twofold axis $\left(Z^{\prime}=1 / 2\right)$ in both structures. The phase transition is of first order with strong hysteresis. The phase transition results in changes to both the intra- and the intermolecular coordination environment.

\section{Introduction}

Dimethyl sulfate $\left(\mathrm{DMSO}_{4}\right)$ is a strong methylating agent used widely and in high volumes in industrial organic synthesis. In addition, under certain circumstances it has application as a sulfonating agent, catalyst, stabilizer and solvent. Its end applications include surfactants, pesticides, water treatment chemicals, dyes and pharmaceuticals. $\mathrm{DMSO}_{4}$ is also of fundamental chemical interest in terms of understanding and predicting the general family of compounds containing sulfurto-oxygen linkages. However, despite the importance of $\mathrm{DMSO}_{4}$, there is no crystal structure information available other than a report of the structure of a 1:1 host-guest complex between $\mathrm{DMSO}_{4}$ and 18-crown-6 (Weber, 1983). Limited spectroscopic and theoretical structural studies have been reported, and these include a recent IR spectroscopy and theoretical study (Borba et al., 2005), electron diffraction and dipolometry studies (Brunvoll et al., 1981), and IR/Raman spectroscopy (Christe \& Curtis, 1972). The dearth of structural information may be explained in large part by the highly toxic nature of the compound. $\mathrm{DMSO}_{4}$ is a lachrymator and likely human carcinogen that is readily absorbed through the skin.

We report here the crystal structures of two low-temperature phases of $\mathrm{DMSO}_{4}$, which, to the best of our knowledge, have not been reported previously. The handling considerations, low melting point and first-order phase transition of $\mathrm{DMSO}_{4}$ represent particular technical difficulties for both powder and single-crystal diffraction techniques. However, the complementary use of both techniques has enabled a full and detailed structural study to be completed.

\section{Experimental}

Dimethyl sulfate, $\left(\mathrm{CH}_{3} \mathrm{O}\right)_{2} \mathrm{SO}_{2}$, is a clear colourless liquid with a melting point of $241 \mathrm{~K}$ and a boiling point of $461 \mathrm{~K}$. Samples
Received 15 August 2005

Accepted 17 January 2006
(C) 2006 International Union of Crystallography Printed in Great Britain - all rights reserved 
of normal $(99+\%)$ and perdeuterodimethyl sulfate $\left(\mathrm{DMSO}_{4^{-}}\right.$ $\left.d_{6}\right),\left(\mathrm{CD}_{3} \mathrm{O}\right)_{2} \mathrm{SO}_{2},(99+\%)$ were obtained from Sigma-Aldrich for the single-crystal X-ray and neutron powder diffraction studies, respectively. The sample is a well known carcinogen and should be handled with care.

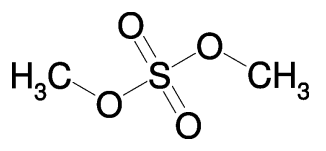

\subsection{Neutron powder diffraction measurements}

Liquid $\mathrm{DMSO}_{4}-d_{6}(5 \mathrm{~g})$ was sealed in an $11 \mathrm{~mm}$-diameter vanadium sample can. The can contained glass wool to promote the growth of fine crystallites on freezing. The sample was loaded in a vanadium-tailed 'orange' cryostat at $100 \mathrm{~K}$ and rapidly cooled to $5 \mathrm{~K}$. Time-of-flight neutron powder diffraction data were collected initially on the OSIRIS spectrometer (Telling \& Andersen, 2005) at the ISIS pulsed neutron source in order to characterize the low-temperature phase behaviour. Data were recorded at $5 \mathrm{~K}$ at backscattering, $\langle 2 \theta\rangle=160^{\circ}$, over a time-of-flight range of between 11.7 and $193.2 \mathrm{~ms}$, corresponding to a $d$-spacing range of between 0.5 and $11 \AA$. Under these experimental settings the instrumental resolution, $\Delta d / d$, is approximately constant and equal to $2 \times 10^{-3}$. The sample was then heated in approximately $10 \mathrm{~K}$ steps up to $230 \mathrm{~K}$ before cooling back to $5 \mathrm{~K}$ in $7 \mathrm{~K}$ steps. At each temperature during this sequence diffraction profiles were recorded for a period of $10 \mu \mathrm{Ah}$ ( ca $12 \mathrm{~min}$ ) over a restricted time-of-flight range of 29.4-69.4 ms (1.7-4.1 $)$.

High-resolution powder data were also recorded using HRPD (Ibberson et al., 1992) at ISIS at $225 \mathrm{~K}(130 \mu \mathrm{Ah}, c a$ $3.5 \mathrm{~h})$ and $5 \mathrm{~K}(68 \mu \mathrm{Ah}, c a 2 \mathrm{~h})$. Data were recorded at backscattering, $\langle 2 \theta\rangle=168^{\circ}$, over a time-of-flight range of between 30 and $130 \mathrm{~ms}$, corresponding to a $d$-spacing range of between 0.6 and $2.6 \AA$. Under these experimental settings the instrumental resolution, $\Delta d / d$, is approximately constant and

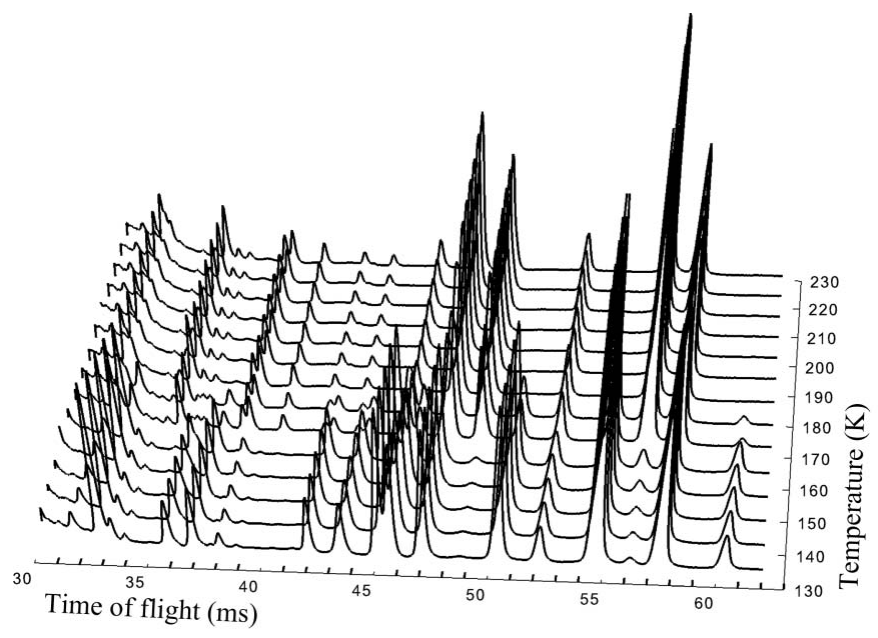

Figure 1

Section of the OSIRIS data thermogram recorded on cooling. equal to $8 \times 10^{-4}$. A standard data reduction procedure was followed for both instruments; the data were normalized to the incident-beam monitor profile and corrected for detector efficiency effects using a previously recorded vanadium spectrum.

A section of the thermogram recorded on OSIRIS on cooling is shown in Fig. 1 and clearly identifies the phase transition around $175 \mathrm{~K}$. The diffraction patterns recorded using OSIRIS at 5 and $230 \mathrm{~K}$ were indexed on the basis of the positions of the first 20 peaks using DICVOL91 (Boultif \& Louër, 1991). At $5 \mathrm{~K}$ the cell is monoclinic: $a=8.674$ (2), $b=$ $5.812(1), c=9.936$ (2) $\AA, \beta=100.42(2)^{\circ}$. At $230 \mathrm{~K}$ the cell is orthorhombic: $a=12.061$ (2), $b=15.907$ (3), $c=5.797$ (1) $\AA$. Both structures were solved by simulated annealing implemented by TOPAS-Academic (Coelho, 2000) using a molecular template based on earlier electron diffraction data (Brunvoll et al., 1981). The phase II structure at $5 \mathrm{~K}$ was solved initially in space group $P 2_{1} / n$. The structure was then refined against the HRPD $5 \mathrm{~K}$ data, and the symmetry was increased to $I 2 / a$ following analysis with the program MISSYM, a component of the PLATON suite (Spek, 2003). Details of the refinement are given in Table $1^{\mathbf{1}}$ and the final profile fit is shown in Fig. 2. The phase I structure was solved in space group $F d d 2$; however, attempts to refine the structure were unsatisfactory. All powder data sets in this phase showed a strong texture, despite the presence of glass wool in the sample can, which could not be modelled adequately. This uncertainty resulted in unrealistic molecular bond lengths and angles following attempts to refine the atomic coordinates and nonphysical values for the isotropic displacement parameters. Under normal circumstances a high-quality powder sample would be produced simply by hand grinding; however, owing to handling issues associated with such a highly toxic material, single-crystal methods were chosen as described below.

The variable-temperature data sets recorded on OSIRIS were subsequently analysed using models based on the final refined structures for each phase. In these refinements the molecular geometry was fixed and the only structural parameters refined were the lattice constants and two atomic displacement parameters: one for $\mathrm{D}$ atoms and one for the remaining $\mathrm{S}, \mathrm{C}$ and $\mathrm{O}$ atoms. In the region of the transition, the coexisting phases were both refined where possible. Data recorded on warming suffered a number of interruptions due to problems with the neutron source. These (three) interruptions are the most likely cause of deviations from the expected smooth variation of the lattice parameters with temperature (Fig. 3). In comparatively rapid measurements such as these, the sample is never in true thermal equilibrium with the surroundings. This does not pose a significant problem if a constant heating and measurement time 'ramp' is maintained. Interrupting this ramp sequence, however, allows the sample to attain true thermal equilibrium and is the cause of the apparent discontinuities in the thermal expansion. By

\footnotetext{
${ }^{1}$ Supplementary data for this paper are available from the IUCr electronic archives (Reference: WS5036). Services for accessing these data are described at the back of the journal.
} 
Table 1

Experimental details for phase II of perdeuterodimethyl sulfate and phase I of dimethyl sulfate.

\begin{tabular}{|c|c|c|}
\hline & Phase II & Phase I \\
\hline \multicolumn{3}{|l|}{ Crystal data } \\
\hline Chemical formula & $\mathrm{C}_{2} \mathrm{D}_{6} \mathrm{O}_{4} \mathrm{~S}$ & $\mathrm{C}_{2} \mathrm{H}_{6} \mathrm{O}_{4} \mathrm{~S}$ \\
\hline$M_{r}$ & 132.17 & 126.13 \\
\hline Cell setting, space group & Monoclinic, $I 2 / a$ & Orthorhombic, $F d d 2$ \\
\hline Temperature (K) & 5 & 220 \\
\hline$a, b, c(\AA)$ & $\begin{array}{l}8.68731(7), 5.82756(4), \\
\quad 9.94376(6)\end{array}$ & $\begin{array}{l}12.0568(7), 15.9176(10), \\
5.8001(4)\end{array}$ \\
\hline$\alpha, \beta, \gamma\left({ }^{\circ}\right)$ & $90.0,100.4404(8), 90.0$ & $90,90,90$ \\
\hline$V\left(\AA^{3}\right)$ & 495.08 & $1113.13(12)$ \\
\hline$Z$ & 4 & 8 \\
\hline$D_{x}\left(\mathrm{Mg} \mathrm{m}^{-3}\right)$ & $1.773(1)$ & 1.505 \\
\hline Radiation type & Time-of-flight neutron & Мo $K \alpha$ \\
\hline $\begin{array}{l}\text { No. of reflections for cell } \\
\text { parameters }\end{array}$ & - & 1014 \\
\hline$\theta$ range $\left({ }^{\circ}\right)$ & - & $3-25$ \\
\hline$\mu\left(\mathrm{mm}^{-1}\right)$ & - & 0.50 \\
\hline $\begin{array}{l}\text { Specimen/crystal form, } \\
\text { colour }\end{array}$ & $\begin{array}{l}\text { Cylinder (particle } \\
\text { morphology: irregular } \\
\text { powder), white }\end{array}$ & Cylinder, colourless \\
\hline Specimen size $(\mathrm{mm})$ & $25 \times 11$ & $4.00 \times 0.75 \times 0.75$ \\
\hline \multicolumn{3}{|l|}{ Data collection } \\
\hline Diffractometer & HRPD, ISIS Facility & Bruker SMART \\
\hline Data collection method & $\begin{array}{l}\text { Specimen mounting: stan- } \\
\text { dard } 11 \text { mm-diameter } \\
\text { cylindrical vanadium } \\
\text { sample holder; time-of- } \\
\text { flight range } 30-130 \mathrm{~ms}\end{array}$ & $\omega$ \\
\hline Total flight path $(\mathrm{m}),\langle 2 \theta\rangle\left(^{\circ}\right)$ & $95.89,168.329$ & - \\
\hline Absorption correction & - & $\begin{array}{l}\text { Multi-scan (based on } \\
\text { symmetry-related } \\
\text { measurements) }\end{array}$ \\
\hline$T_{\min }$ & - & 0.37 \\
\hline$T_{\max }$ & - & 0.69 \\
\hline $\begin{array}{l}\text { No. of measured, indepen- } \\
\text { dent and observed reflec- } \\
\text { tions }\end{array}$ & - & $2198,742,594$ \\
\hline $\begin{array}{l}\text { Criterion for observed } \\
\text { reflections }\end{array}$ & - & $I>2 \sigma(I)$ \\
\hline$R_{\text {int }}$ & - & 0.043 \\
\hline$\theta_{\max }\left({ }^{\circ}\right)$ & - & 30.4 \\
\hline Range of $h, k, l$ & - & $-16 \Rightarrow h \Rightarrow 16$ \\
\hline & - & $-21 \Rightarrow k \Rightarrow 21$ \\
\hline & - & $-6 \Rightarrow l \Rightarrow 8$ \\
\hline \multicolumn{3}{|l|}{ Refinement } \\
\hline Refinement on & Rietveld method & $F^{2}$ \\
\hline$R$ factors and goodness-of-fit & $\begin{array}{l}R_{p}=0.046, R_{\mathrm{wp}}=0.056 \\
\quad R_{\exp }=0.030, S=1.64\end{array}$ & $\begin{array}{l}R\left[F^{2}>2 \sigma\left(F^{2}\right)\right]=0.034 \\
\quad w R\left(F^{2}\right)=0.086, S=0.93\end{array}$ \\
\hline $\begin{array}{l}\text { Wavelength of incident } \\
\text { radiation }(\AA)\end{array}$ & $1.24-5.36$ & - \\
\hline Excluded region(s) & None & - \\
\hline Profile function & $\begin{array}{l}\text { TOPAS TOF Profile } \\
\text { function }\end{array}$ & - \\
\hline Reflection/profile data & - & 740 reflections \\
\hline No. of parameters & 69 & 47 \\
\hline $\mathrm{D} / \mathrm{H}$-atom treatment & Refined independently & Refined independently \\
\hline Weighting scheme & Based on measured s.u.'s & $w=1 /\left[\sigma^{2}\left(F^{2}\right)+0.05\right]$ \\
\hline$(\Delta / \sigma)_{\max }$ & 0.04 & $<0.0001$ \\
\hline$\Delta \rho_{\max }, \Delta \rho_{\min }\left(\mathrm{e} \AA^{-3}\right)$ & - & $0.17,-0.11$ \\
\hline Extinction method & - & Larson (1970), equation 22 \\
\hline Extinction coefficient & - & $42(9)$ \\
\hline Absolute structure & - & $\begin{array}{l}\text { Flack (1983), } 204 \text { Friedel } \\
\text { pairs }\end{array}$ \\
\hline Flack parameter & - & $0.14(12)$ \\
\hline
\end{tabular}

Computer programs used: ISIS Instrument Control Program (ICP), SMART (Siemens, 1993), TOPASAcademic (Coelho, 2000), SAINT (Siemens, 1995), standard HRPD normalization routines, DIRDIF-96 (Beurskens et al., 1996), CRYSTALS (Betteridge et al., 2003), ORTEP-3 (Farrugia, 1997), PLATON (Spek, 2003), CAMERON (Watkin et al., 1996). contrast, no such major interruptions were experienced while recording data on cooling, as can be seen in the figure.

\subsection{X-ray single-crystal diffraction measurements}

Liquid $\mathrm{DMSO}_{4}$ was loaded into a capillary of $0.75 \mathrm{~mm}$ diameter. Data were collected on a Bruker SMART APEX CCD diffractometer equipped with an Oxford Cryosystems low-temperature device and an OHCD laser-assisted crystal growth device (Boese \& Nussbaumer, 1994). The crystal was grown at $220 \mathrm{~K}$ using the Boese laser-assisted zone refinement method. The diffraction pattern was indexed using GEMINI (Sparks, 1999) and integrated with SAINT (Siemens, 1995). 63 reflections were used for indexing, and of these 36 could be indexed using one orientation matrix and 23 of the remaining 27 reflections were indexed to a second matrix. The sample is thus composed mainly of two crystals, but the twin law is such that reflection overlap between domains was not expected to be a significant problem. Accordingly all subsequent manipulations were carried out using a single orientation matrix and the data collection strategy was optimized using COSMO (Bruker, 2003) to collect a hemisphere of data in the range $2 \theta<54^{\circ}$. The structure was solved by Patterson methods DIRDIF (Beurskens et al., 1996) in space group Fdd2. Details of the refinement using CRYSTALS (Betteridge et al., 2003) are given in Table 1.

The sample was then cooled to $180 \mathrm{~K}$ and a second data set collected. The crystal was shown to have undergone a transition to a monoclinic I-centred phase. 893 reflections were used for indexing and all but 43 could be indexed on one of five orientation matrices. It is interesting to note that the benefit of the reconstructive phase transition in the powder study of breaking up crystallites has now become problematic in the single-crystal study. The structure was again solved using Patterson methods (see supplementary data) and found to be in agreement with the phase II structure of the powder study.

\section{Results}

\subsection{The phase I crystal structure}

The structure of phase $\mathrm{I} \mathrm{DMSO}_{4}$ has half a molecule in the asymmetric unit with the central $\mathrm{S}$ atom located on a twofold axis. The molecules interact via four main $\mathrm{H} \cdot \mathrm{H}$ contacts in the range 2.53 (2)-3.09 (2) $\AA$. (Here the $\mathrm{C}-\mathrm{H}$ bonds have been normalized to $1.08 \AA$ to enable direct comparison with the neutron-derived phase II structure described below.) The shortest contact between $\mathrm{H} 42$ and $\mathrm{H} 43$ (following the symmetry 
operation $\frac{1}{2}-x,-y, \frac{1}{2}+z$ ) forms zigzag chains of $\mathrm{H} \cdots \mathrm{H}-\mathrm{C}-$ $\mathrm{H} \cdots \mathrm{H}$ interactions linking two columns of molecules projected onto the $a c$ plane. These molecular chains are in turn cross-linked by a single short contact between $\mathrm{H} 41$ and $\mathrm{O} 2$ (following the symmetry operation $\frac{1}{4}-x, \frac{1}{4}+y,-\frac{3}{4}+z$ ) of 2.29 (2) $\AA$ in the [012] and [012] direction. The structure is illustrated in Fig. 4.

Within this crystal structure the molecule exhibits $C_{2}$ symmetry and adopts a $\mathrm{V}$-shaped molecular conformation consistent with the most stable conformer determined by matrix-isolation FT-IR spectroscopy and theoretical methods (Borba et al., 2005). The $\mathrm{C}-\mathrm{O}-\mathrm{S}-\mathrm{O}$ torsion angle is $68.13(11)^{\circ}$ compared with $74.3^{\circ}$ from theory. The gas-phase electron diffraction studies (Brunvoll et al., 1981) also report such a $\mathrm{V}$-shaped conformation, albeit with a much reduced $\mathrm{C}-\mathrm{O}-\mathrm{S}-\mathrm{O}$ torsion angle of $47(2)^{\circ}$. The methyl group conformation in the phase I structure has one $\mathrm{C}-\mathrm{H}$ bond antiperiplanar relative to the $\mathrm{S}-\mathrm{O} 2$ bond and is also in agreement with the spectroscopic and theoretical studies discussed above. The libration of the molecule in the structure is high but not unexpectedly so at $200 \mathrm{~K}$, which is close to the melting point of $241 \mathrm{~K}$. Selected intramolecular dimensions corrected for libration are given in Table 2.

\subsection{The phase II crystal structure}

The structure of phase II $\mathrm{DMSO}_{4}$ similarly has half a molecule in the asymmetric unit with the central $\mathrm{S}$ atom sitting on a twofold axis. The short $c a 5.8 \AA$ axis in phase $\mathrm{I}$ is retained as the $b$ axis in the phase II structure, and in this case the molecules interact via six main $\mathrm{D} \cdots \mathrm{D}$ contacts in the range 2.470 (2)-3.032 (2) §. The shortest of these contacts is between D41 and D42 (following the symmetry operation

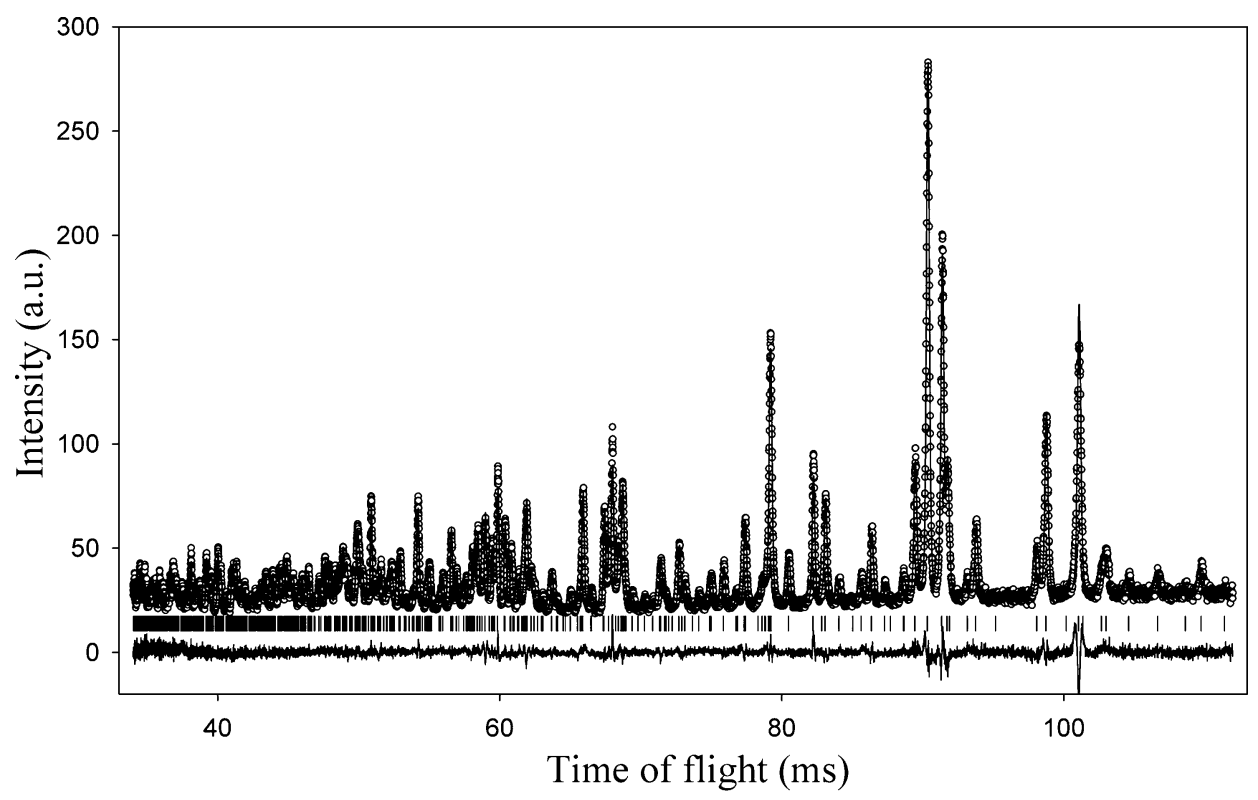

Figure 2

The final Rietveld plot of phase II at $5 \mathrm{~K}$, showing observed (o), calculated (line) and difference (lower) profiles. Vertical bar markers indicate the calculated Bragg peak positions. The equivalent $d$-spacing range corresponds to $0.7-2.4 \AA$.
Table 2

Intramolecular bond lengths $(\AA)$ and angles $\left(^{\circ}\right)$ for dimethyl sulfate.

\begin{tabular}{|c|c|c|}
\hline & Phase I (5 K) & Phase II $(220 \mathrm{~K}) \dagger$ \\
\hline $\mathrm{S} 1-\mathrm{O} 2$ & $1.424(1)$ & $1.403(2), 1.425$ \\
\hline $\mathrm{S} 1-\mathrm{O} 3$ & $1.561(1)$ & $1.530(2), 1.556$ \\
\hline $\mathrm{O} 3-\mathrm{C} 4$ & $1.442(2)$ & $1.455(3), 1.474$ \\
\hline $\mathrm{C} 4-\mathrm{H} 41$ & $1.085(2)$ & $0.94(2)$ \\
\hline $\mathrm{C} 4-\mathrm{H} 42$ & $1.078(2)$ & $0.93(2)$ \\
\hline $\mathrm{C} 4-\mathrm{H} 43$ & $1.108(2)$ & $0.95(2)$ \\
\hline $\mathrm{O} 2-\mathrm{S} 1-\mathrm{O} 3$ & $111.00(7)$ & $109.67(11)$ \\
\hline $\mathrm{O} 2-\mathrm{S} 1-\mathrm{O} 2^{\mathrm{i}}$ & $118.97(10)$ & $120.9(2)$ \\
\hline $\mathrm{O} 2-\mathrm{S} 1-\mathrm{O} 3^{\mathrm{i}}$ & $105.53(6)$ & $105.62(15)$ \\
\hline $\mathrm{O} 3-\mathrm{S} 1-\mathrm{O}^{\mathrm{i}}$ & $103.85(9)$ & $104.22(12)$ \\
\hline $\mathrm{S} 1-\mathrm{O} 3-\mathrm{C} 4$ & $116.89(9)$ & $117.43(15)$ \\
\hline $\mathrm{O} 3-\mathrm{C} 4-\mathrm{H} 41$ & $105.70(13)$ & $107.5(15)$ \\
\hline $\mathrm{O} 3-\mathrm{C} 4-\mathrm{H} 42$ & $111.56(14)$ & $108.4(15)$ \\
\hline $\mathrm{O} 3-\mathrm{C} 4-\mathrm{H} 43$ & $109.71(15)$ & 109.9 (16) \\
\hline $\mathrm{S} 1-\mathrm{O} 3-\mathrm{C} 4-\mathrm{H} 41$ & $158.32(10)$ & $179.2(17)$ \\
\hline
\end{tabular}

$\dagger$ Figures in italics are libration-corrected bond lengths. Symmetry codes: (i) $\frac{1}{2}-x, y$, $-z$ in phase II; $-x,-y, z$ in phase $\mathrm{I}$.

$\left.1-x, \frac{1}{2}+y, \frac{1}{2}-z\right)$ and links the molecules into sheets in the crystallographic ac plane, as illustrated in Fig. 5. Despite these changes in the crystal packing motif the intramolecular geometry is largely retained. The $\mathrm{C}-\mathrm{O}-\mathrm{S}-\mathrm{O}$ torsion angle is reduced by only $2-64.56^{\circ}$. The main change in molecular conformation in phase II is that the methyl groups are rotated by $20^{\circ}$ compared with the ideal conformation observed in phase I (Table 2).

\section{Discussion of the phase I and phase II structures and phase transition behaviour}

The molecular dimensions and conformation in the two phases are unexceptional and in remarkable agreement (Table 2). There is also broad agreement with the molecular dimensions for the $\mathrm{DMSO}_{4}$ complex with 18-crown-6 (Weber, 1983). In the latter, no molecular symmetry is imposed by the crystal structure and the equivalent $\mathrm{S} 1-\mathrm{O} 2$ bond lengths are 1.405 (6) and 1.416 (6) $\AA$, and for $\mathrm{S} 1-\mathrm{O} 3 \quad 1.544(4) \quad$ and 1.525 (4) ^. The methyl group conformation in the host-guest complex leads to equivalent $\mathrm{S} 1-$ $\mathrm{O} 3-\mathrm{C} 4-\mathrm{H} 41$ torsion angles of 178 and $-167^{\circ}$, which are approaching the ideal conformation and are in line with the phase I structure.

The variation in the unit-cell volume of the phase I and phase II structures is shown in Fig. 3. There is a large hysteresis associated with the transition temperature; on warming $T_{\mathrm{c}} \simeq 210 \mathrm{~K}$ and on cooling 
$T_{\mathrm{c}} \simeq 175 \mathrm{~K}$. This hysteresis and the coexistence of both phases in the region of the transition are characteristic of first-order

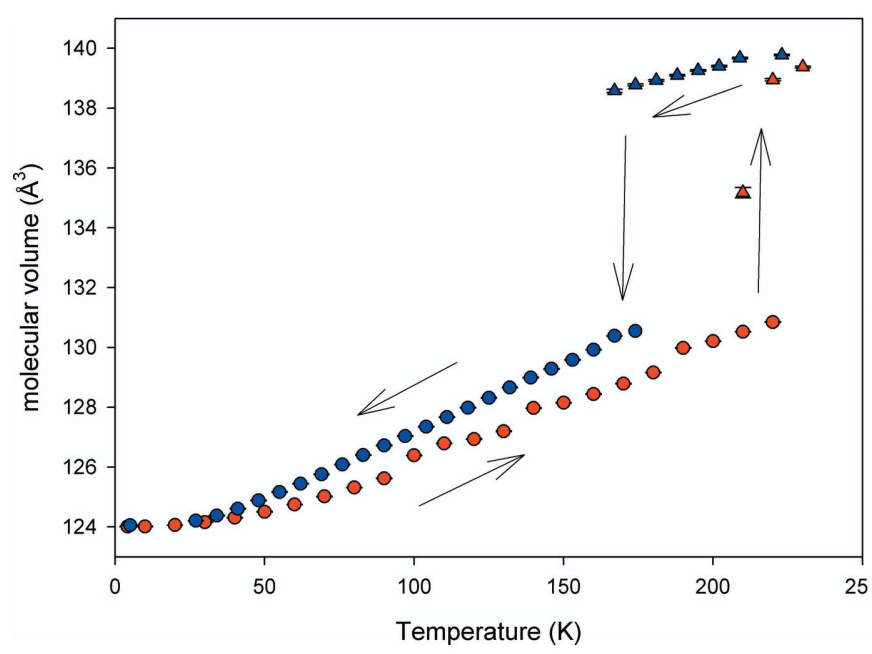

(a)

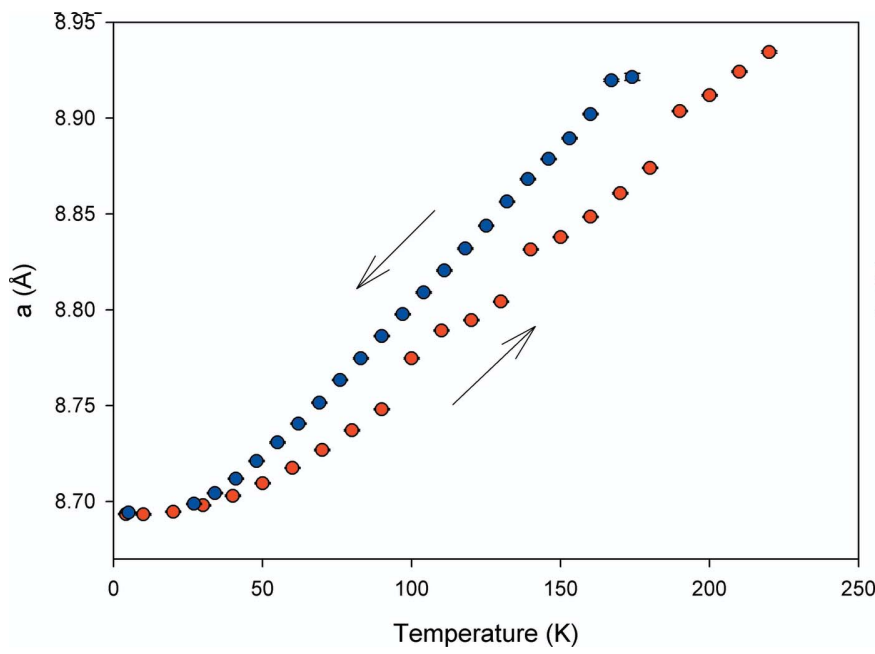

(b)

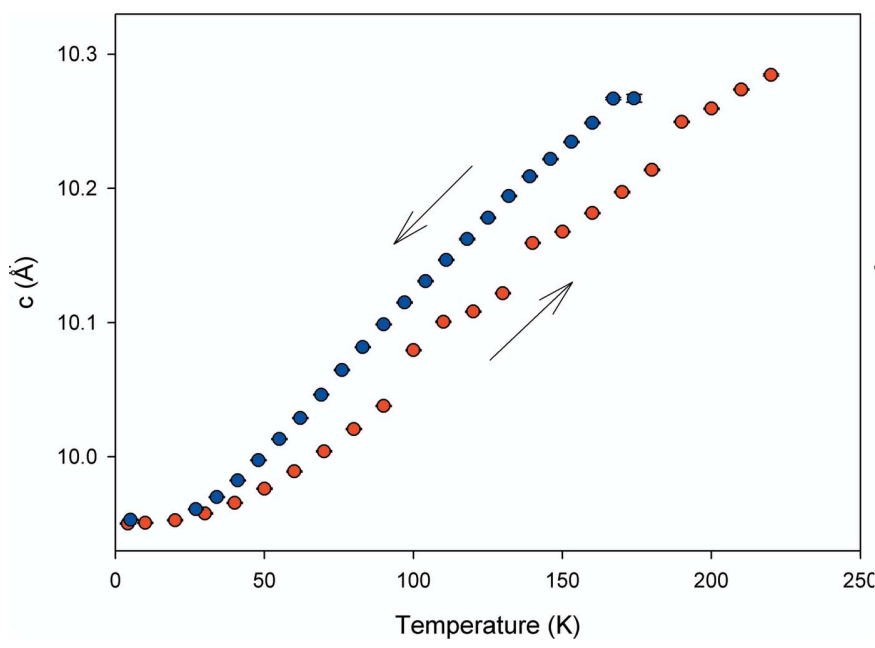

(d) behaviour. Below the transition temperature, the cell volume, the $a$ and $c$ axes, and the $\beta$ angle of the phase II structure all show a smooth decrease with temperature. In contrast, the $b$ axis shows a small but significant increase with decreasing temperature.

Analysis of the Voronoi-Dirichlet polyhedron constructed only on the basis of the distribution of the molecular centroids (the 'lattice' VDP) in phase I (high- $T$ phase; Fig. 6) shows that the coordination sequence is 14-52-114. This is close to bodycentred cubic topology (perfect CS $=14-50-110$ ), and is characterized by eight centroid-centroid distances in the range 6.62-6.69 $\AA$, and six in the range 5.20-5.80 $\AA$. A similar analysis of phase II yields the same coordination sequence with two distances of $7.60 \AA$, four of $6.73 \AA$ and eight of 5.13$5.81 \AA$. Following Peresypkina \& Blatov $(2000 a, b)$ in neglecting the very shortest contacts and recalculating the coordination sequence yields $12-42-92$. This corresponds to cubic close-packed topology and hence the more efficient

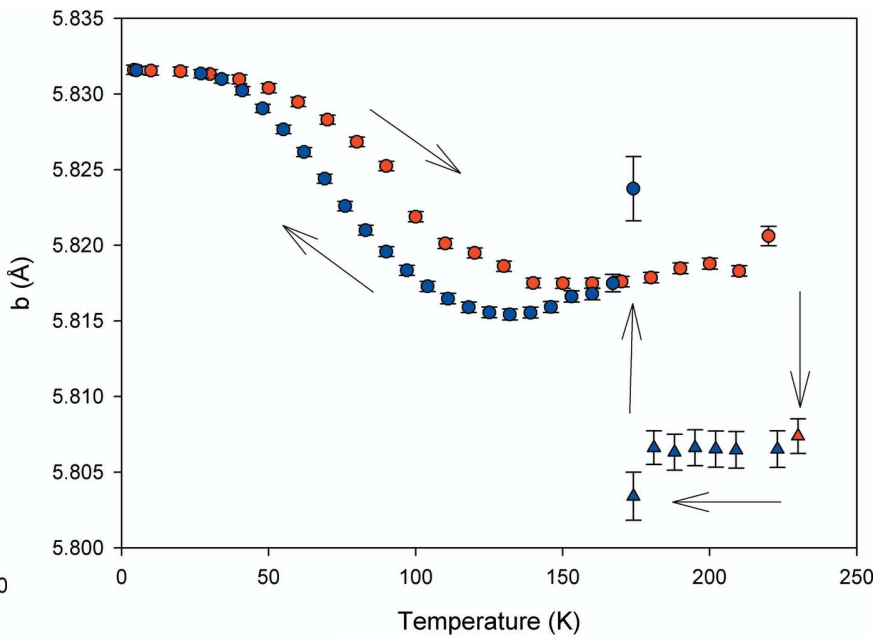

(c)

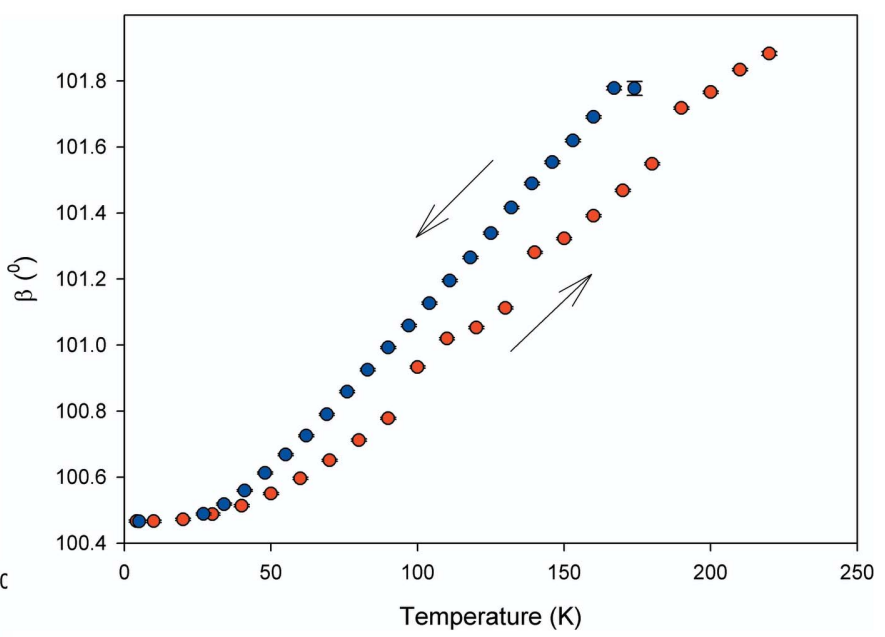

(e)

Figure 3

Variation of the unit-cell parameters for $\mathrm{DMSO}_{4}-\mathrm{d}_{6}$ phase II (o) and phase I $(\Delta)$ where shown. $(a)$ Molecular volume; $(b) a$ lattice constant; $(c) b$ lattice constant and the corresponding $c$ lattice constant in phase I; $(d) c$ lattice constant. $(e) \beta$ angle. 
packing of phase II. This packing is confirmed by a significant reduction in the molecular volume at the transition. For example, in phase $\mathrm{I}$ at $167 \mathrm{~K}$ each molecule occupies $138.57(5) \AA^{3}$ compared with $130.38(1) \AA^{3}$ in phase II, a decrease of some $6 \%$. The reduction in molecular volume is accompanied by a related reduction in the intermolecular $\mathrm{H} \cdots \mathrm{H}$ close contacts as described above. This optimal structure is realized with the accompanying changes to the methyl group conformation away from the ideal theoretical prediction.

Finally, anomalous behaviour is observed in the unit-cell expansion of phase II when compared on warming and cooling. At $5 \mathrm{~K}$ the unit-cell volumes and lattice constants in the two cases are equivalent (Fig. 3). However, above $50 \mathrm{~K}$ the thermal expansivity of the cell volume for the heating

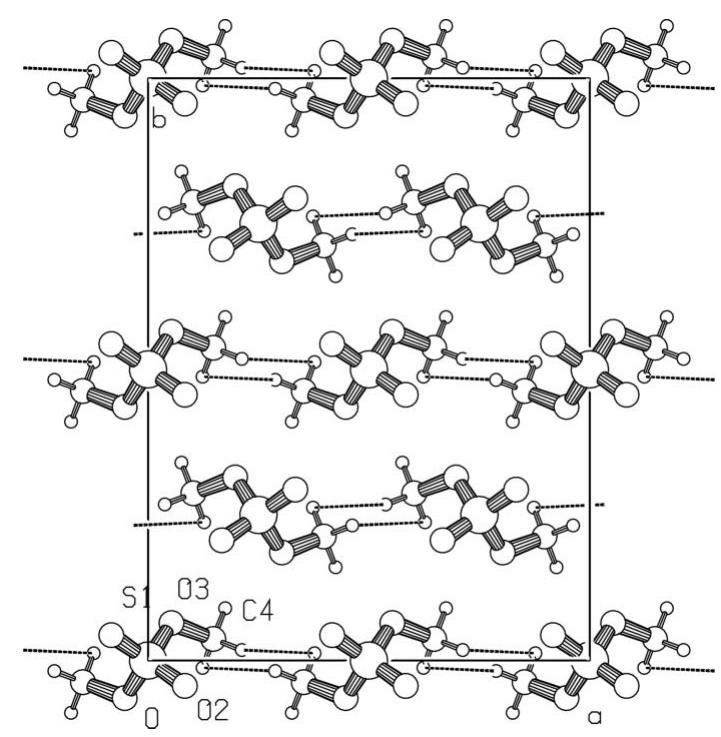

Figure 4

A view of the phase I structure of $\mathrm{DMSO}_{4}$ projected on to the crystallographic $a b$ plane. The shortest $\mathrm{H} \cdots \mathrm{H}$ contacts are shown as broken lines and described in the main text.

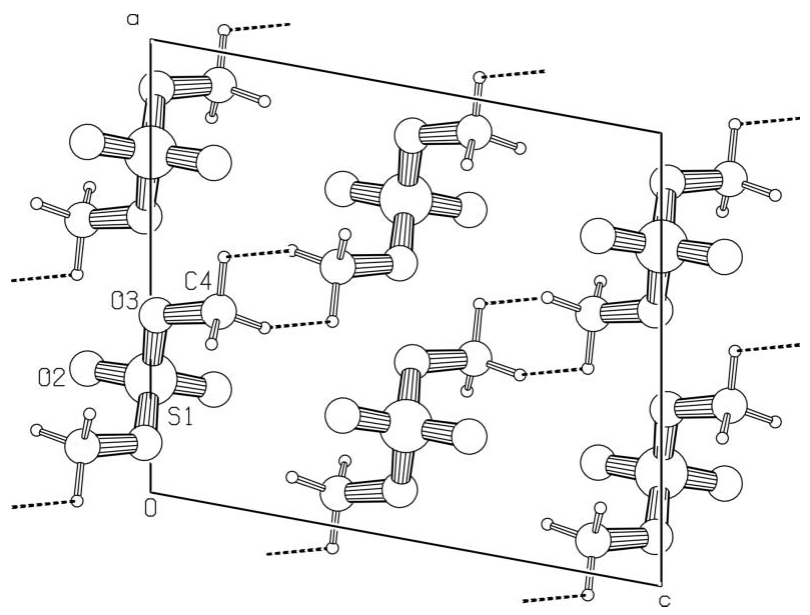

Figure 5

A view of the phase II structure of $\mathrm{DMSO}_{4}-d_{6}$ projected on to the crystallographic $a c$ plane. The shortest $\mathrm{D} \cdots \mathrm{D}$ contacts are shown as broken lines and described in the main text. sequence is markedly lower when compared with the cooling sequence. Similar behaviour is shown by the $a, c$ and $b$ lattice constants, whereas the $b$ lattice constant exhibits a less negative expansion. The thermal treatment of the sample offers a likely explanation for this observation. The sample was initially quenched at $100 \mathrm{~K}$ and then cooled to $5 \mathrm{~K}$. Data recorded on warming this sample were composed entirely of the phase II structure until the transition onset around $210 \mathrm{~K}$. In contrast, the phase II sample for the cooling sequence was transformed via the phase I structure and lattice parameters for both phases could be refined down to $167 \mathrm{~K}$. Very weak peaks corresponding to the phase I structure were in fact observed down to $100 \mathrm{~K}$. The intergrowth of phase II and phase I structures and sluggish nature of the transition would both affect the observed thermal expansivity of phase II in the cooling sequence.

\section{Conclusions}

The smaller molecular volume of $\mathrm{DMSO}_{4}$ in the phase II structure as compared with the phase I structure is accompanied by a rotation of the methyl groups away from ideal $C_{2}$ molecular symmetry found in the gas phase and phase I crystal structure. The first-order transition into phase II is thus driven

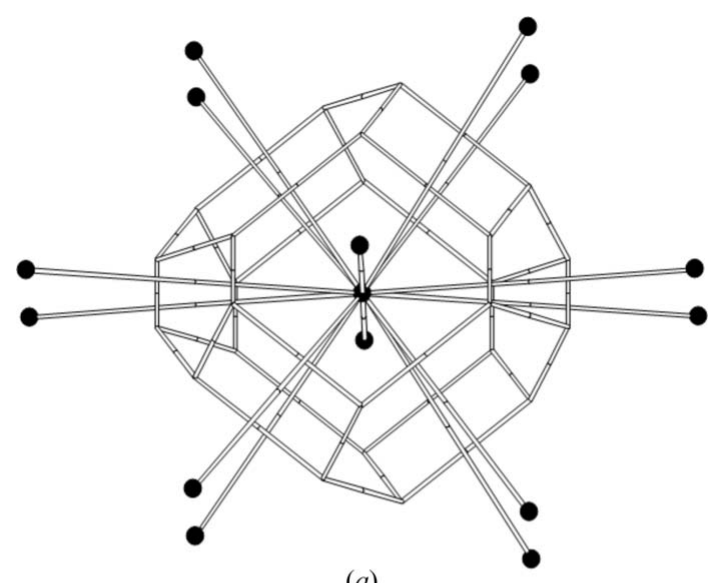

(a)

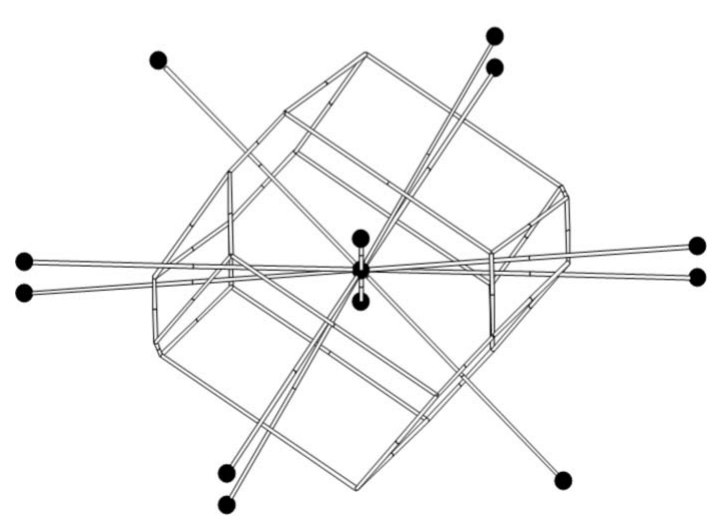

(b)

Figure 6

Views of the lattice VDPs along the $\sim 5.8 \AA$ axis of phase I ( $a$ ) and phase II $(b)$. (This corresponds to the $c$ and $b$ crystallographic axes, respectively.) 
by relieving the intermolecular steric interactions at the expense of retaining a near ideal intramolecular conformation.

This work has been supported by the CCLRC with the provision of neutron beam time.

\section{References}

Betteridge, P. W., Carruthers, J. R., Cooper, R. I., Prout, K. \& Watkin, D. J. (2003). J. Appl. Cryst. 36, 1487.

Beurskens, P. T., Beurskens, G., Bosman, W. P., de Gelder, R., Garcia Granda, S., Gould, R. O., Israel, R. \& Smits, J. M. M. (1996). DIRDIF-96. University of Nijmegen, Toernooiveld 1, 6525 ED Nijmegen, The Netherlands.

Boese, R. \& Nussbaumer, M. (1994). Correlations, Transformations and Interactions in Organic Chemistry, IUCr Crystallographic Symposia, Vol. 7, edited by D. W. Jones \& A. Katrusiak. Oxford University Press.

Borba, A., Gómez-Zavaglia, A., Simões, P. N. N. L. \& Fausto, R. (2005). Spectrochim. Acta Part A, 61, 1461-1470.

Boultif, A. \& Louër, D. (1991). J. Appl. Cryst. 24, 987-993.

Bruker (2003). COSMO. Bruker-Nonius Inc., Madison, Wisconsin, USA.

Brunvoll, J., Exner, O. \& Hargittai, I. (1981). J. Mol. Struct. 73, 99104.
Christe, K. O. \& Curtis, E. C. (1972). Spectrochim. Acta Part A, 28, 1889-1898.

Coelho, A. A. (2000). J. Appl. Cryst. 33, 899-908.

Farrugia, L. J. (1997). J. Appl. Cryst. 30, 565.

Flack, H. D. (1983). Acta Cryst. A39, 876-881.

Ibberson, R. M., David, W. I. F. \& Knight, K. S. (1992). Report RAL92-031. Rutherford Appleton Laboratory, Chilton, Didcot, Oxfordshire, UK.

Larson, A. C. (1970). Crystallographic Computing, edited by F. R. Ahmed, S. R. Hall \& C. P. Huber, pp. 291-294. Copenhagen: Munksgaard.

Peresypkina, E. V. \& Blatov, V. A. (2000a). Acta Cryst. B56, 501-511.

Peresypkina, E. V. \& Blatov, V. A. (2000b). Acta Cryst. B56, 10351045.

Siemens (1993). SMART. Siemens Industrial Automation Inc., Madison, Wisconsin, USA.

Siemens (1995). SAINT. Siemens Industrial Automation Inc., Madison, Wisconsin, USA.

Sparks, R. A. (1999). GEMINI. Bruker AXS Inc., Madison, Wisconsin, USA.

Spek, A. L. (2003). J. Appl. Cryst. 36, 7-13.

Telling, M. T. F. \& Andersen, K. H. (2005). Phys. Chem. Chem. Phys. 7, 1255-1261.

Watkin, D. J., Prout, C. K. \& Pearce, L. J. (1996). CAMERON. Chemical Crystallography Laboratory, University of Oxford, UK. Weber, G. (1983). J. Mol. Struct. 98, 333-336. 